\title{
Erythema Multiforme Associated with Herpetic Pharyngitis
}

Original Image

ORCID ID of the author: S.D. 0000-0003-2293-5547.

Cite this article as: Das S. Erythema Multiforme Associated with Herpetic

Pharyngitis. Turk Arch Otorhinolaryngol 2019; 57(2): 109-10.

\section{Corresponding Author:}

Soumyajit Das; drsoumya_entamch@rediffmail.com

Received Date: 27.03.2019

Accepted Date: 19.05 .2019

Available Online Date: 24.06 .2019

D0I:10.5152/ta0.2019.4309
A 22-year-old female presented with severe throat pain of two days duration with fever. Clinical examination revealed multiple small ulcerative lesions in the left side of the oropharynx involving the anterior pillar of the tonsil and the uvula (Figure 1). A clinical diagnosis of herpetic pharyngitis was made, and the patient was started on valacyclovir. The patient developed multiple non-pruritic exanthematous erythematous lesions in the lower limbs

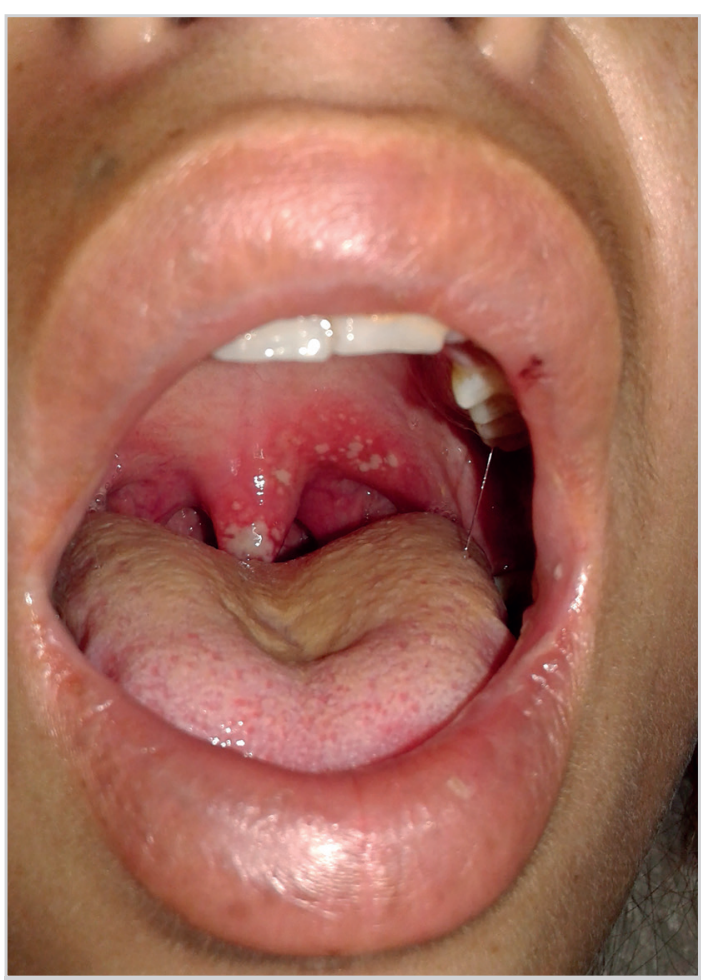

Figure 1. View of herpetic lesions on the palate and the uvula on the third day after initial symptoms (Figure 2). A short course of oral prednisolone was started, and the rashes resolved by the 10th day. There was no recurrence of the symptoms at later follow up.

Erythema multiforme (EM) is a hypersensitivity reaction of the skin to various agents with typical cutaneous and/or mucosal manifestations (1). The condition is often self-limiting but may be recurrent. The presentation of EM may vary, but most of the lesions are erythematous papular lesions. HSV is the most common microbial agent causing EM and accounts for $50 \%$ of the cases (2). HSV associ-

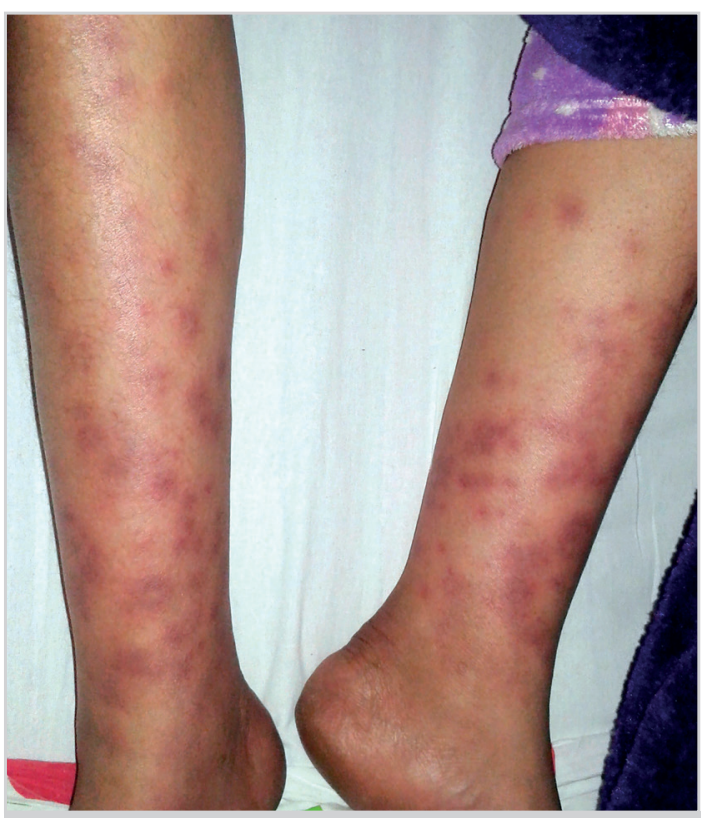

Figure 2. View of erythematous lesions on the lower limbs 
Das $\mathrm{S}$.

ated EM can recur at times and may be precipitated by exposure to sun (3). Various mechanisms have been postulated regarding the pathogenesis of EM. Mostly it is considered to be a Type 4 hypersensitivity reaction mediated by $\mathrm{T}$ lymphocytes. This may be triggered by numerous pathogens like HSV I, HSV II, Mycoplasma pneumonia, EBV, HIV, cytomegalovirus, Mycobacterium leprae and Varicella-zoster virus. Various medications and vaccines are also known to precipitate such lesions (4).

Informed Consent: Written informed consent was obtained from the patient who participated in this study.

Peer-review: Externally peer-reviewed.

Conflict of Interest: The authors have no conflicts of interest to declare.
Financial Disclosure: The authors declared that this study has received no financial support.

\section{References}

1. Kamala KA, Ashok L, Annigeri RG. Herpes associated erythema multiforme. Contemp Clin Dent 2011; 2: 372-5. [CrossRef]

2. Hafsi W, Badri T. Erythema Multiforme. In: StatPearls [Internet]. Treasure Island (FL): StatPearls Publishing; 2019 Jan. Available from: URL: https://www.ncbi.nlm.nih.gov/books/NBK470259/.

3. Weston WL, Morelli JG. Herpes simplex virus-associated erythema multiforme in prepubertal children. Arch Pediatr Adolesc Med 1997; 151: 1014-6. [CrossRef]

4. Celentano A, Tovaru S, Yap T, Adamo D, Aria M, Mignogna $\mathrm{MD}$. Oral erythema multiforme: trends and clinical findings of a large retrospective European case series. Oral Surg Oral Med Oral Pathol Oral Radiol 2015; 120: 707-16. [CrossRef] 